\title{
Electrical Performance Tester for a Double Frequency Unit of a Power supply Vehicle
}

\author{
Xiaoquan $\mathrm{Li}^{1 *}$, Zheng $\mathrm{Liu}^{1}$, and $\mathrm{Tao} \mathrm{Pu}^{1}$ \\ ${ }^{1}$ Air Force Engineering University Air and Missile Defense College, Shaanxi Xi'an,710051,China \\ *Ixq389@126.com
}

Keywords: Double frequency unit, Intelligent detection, Signal processing, Data acquisition, Electricity performance parameter

\begin{abstract}
As a result of the army equipped with a power supply vehicle lack of power parameter testing equipment at the present time, in order to ensure that the double frequency unit after overhaul can meet the factory requirements, a double frequency unit of power supply electrical performance tester was developed. The tester with intelligent detection technology could carry out high-precision, high-speed intelligent testing and analysis waveform for double frequency unit electrical performance parameters. The practical application shows that the tester has a high degree of automation, high precision and high accuracy, and can meet the requirements of each index, and has wide application prospect and development potential. The main function of the tester, tactical technical indicators, composition and working principle were introduced in this paper.
\end{abstract}

\section{Introduction}

The main role of a power supply vehicle in a surface to air missiles weapon system is to provide power to the main and auxiliary vehicles. Whether the double frequency unit in the power supply vehicle can work reliably and even the quality of the power supply is in good order plays a vital role in the smooth operation of the war. Moreover timely grasping of the working state of double frequency unit and accurate detection of the parameters of the unit is the premise of reliable operation of a double frequency unit. In addition, whether power supply parameters of double frequency unit in the power vehicle after overhaul are normal, can meet the factory requirements also play a key role on the power supply quality after its equipment for army。

At present, various types of power vehicles equipped with surface to air missile army have not the corresponding unit parameter testing equipment, the unit in disassemble and overhaul can not achieve monitoring operation, and it even affects the maintenance efficiency. Although many people at home and abroad have made some research on the detection of unit parameters, and some have developed the corresponding testing equipment, but the domestic similar products are not yet able to carry out parameter detection for the power frequency units and intermediate frequency units at the same time. In order to improve the quality of power supply and the reliability of double frequency unit, this paper uses intelligent detection technology to develop a double frequency unit electrical performance tester, which can test various parameters of double frequency unit and analyze, save, display and print the test results, in order to improve the quality of power supply system of weapons and ensure the smooth operation.

\section{Main functions}

It can test the steady-state parameters, transient parameters of the power frequency units and intermediate frequency units simultaneously or separately, and the load can be increased or 
decreased by manual way or automatic way.

The test parameters can be displayed on the computer screen in real time, steady-state waveform and dynamic characteristics can be displayed by the virtual oscilloscope, test data automatically added to the database, and the test report will be automatically printed out according to a certain format.

The test data can be automatically recorded according to the process requirements and also can be manually recorded.

The test channel will be measured and tested to correct system error.

The test database can be queried and managed, all the test data and graphics including steady-state, dynamic process can be stored and queried.

\section{Main technical indicators}

\section{Electrical performance parameters of the intermediate frequency unit}

Voltage: $0 \sim 500 \mathrm{~V}$, Accuracy: $\pm 0.5 \%$.

Current:0 750A, Accuracy: $\pm 0.5 \%$.

Frequency:350 450Hz, Accuracy: $\pm 0.2 \%$.

Power:35kW, Accuracy: $\pm 0.5 \%$.

Power factor:0.1 1.0, Indicating error: $\pm 1 \%$.

\section{Electrical performance parameters of power frequency unit}

Voltage:0 500V, Accuracy: $\pm 0.5 \%$.

Current:0 750A, Accuracy: $\pm 0.5 \%$.

Frequency:40 70Hz, Accuracy: $\pm 0.2 \%$.

Power: $35 \mathrm{~kW}$, Accuracy: $\pm 0.5 \%$.

Power factor:0.1 1.0, Indicating error: $\pm 1 \%$.

\section{System load capacity}

Power frequency and intermediate frequency system can test separately $0.25 \mathrm{~kW}$ to $35 \mathrm{~kW}$ level of generating units; Power frequency and intermediate frequency system stand-alone can carry out resistive and inductive load adjustment, unbalanced adjustment.

Power frequency and intermediate frequency resistive load power is $35 \mathrm{KW}$ (two sets), loading according to $25 \% 50 \%, 75 \%$ ' $100 \%, 110 \%$ level.

two sets of power frequency and medium frequency inductive load capacity of $30 \mathrm{kVA}-400 \mathrm{~V}$, adjustable reactor, the inductance can be continuously adjusted, in the application inductance can be closed-loop adjusted by power factor detection, , according to the size of the load the size of the inductor will be automatically selected.

\section{Console power supply}

Three-phase four-wire $380 \mathrm{~V} 50 \mathrm{~Hz}$, no greater than $10 \mathrm{KW}$.

\section{Conditions of use}

Ambient temperature: $0^{\circ} \mathrm{C} \sim 40^{\circ} \mathrm{C}$.

Relative humidity: less than $90 \%$ temperature at $25^{\circ} \mathrm{C}$.

Above sea level: less than $2000 \mathrm{~m}$. 


\section{Composition and working principle}

\section{Composition}

Power vehicle double frequency unit electrical performance tester is composed of the industrial-grade computer system, signal conditioning control box, console, load control cabinet and load five parts, the system composition shown in Figure 1.

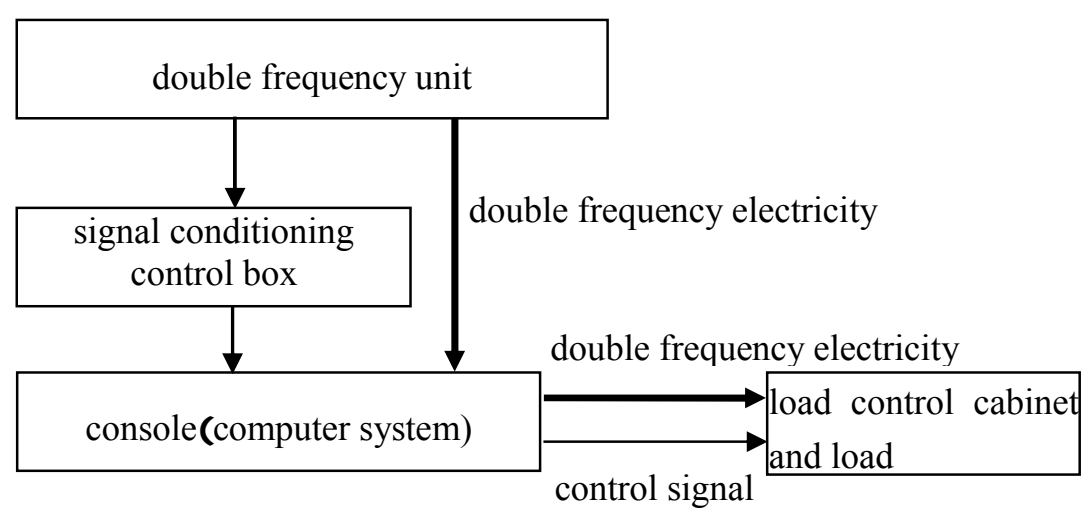

Fig.1 Composition of electrical performance tester

The console is mainly composed of IPC, various digital instrument and control panel etc. Among them the industrial computer is the core of the console, mainly responsible for the collection and processing of data, control and regulation of load, display, output test results, save data and printing reports and other tasks. The console and the double frequency generator are connected by a dedicated double frequency power cable and signal cable. Power cable is responsible for sending the double frequency power that the units produce to the console, and the signal cable is responsible for sending signal from unit's various types of power detection sensor or transmitter to the console. The console and the load cabinet are also connected by dedicated double frequency power cable and control cable, which control cable is responsible for carrying various control signals that console sends to the load cabinet including manual automatic loading and unloading control. Microcomputer measurement and control system mainly completes the data acquisition and testing, calculation and analysis, data management and load control. Measurement and control box is used for power supply dynamic test, composed of power detection sensor, signal conditioning circuit etc. dynamic voltage test use LEM voltage sensor, discrete voltage signals is collected through the A/D acquisition card, and then the software calculates the voltage RMS of each cycle. The dynamic frequency measurement process is as follows. Firstly the signal conditioning circuit conditioning the sine wave into square wave, and then the high-speed counting card calculates the cycle of each cycle of wave, and finally IPC calculates the frequency of each cycle. Digital instrument is multi-function instrument which can real-time display stability parameters of two power supply, namely three-phase voltage, three-phase current, frequency, power factor, it also can transfer power supply parameters through the RS485 serial communication to the computer ,display power steady-state parameters, achieve data record storage. The load control uses the contactor to control the load switching, the equipment includes two sets of the power frequency and intermediate frequency resistive and inductive load switchgear, and they can realize the function of the manual and the automatic load. Panel control achieves the function of manual power load control and electrical parameters of the test, including the power load control mode selection, resistive load, inductive load control and total load selection control buttons. 


\section{System hardware configuration}

The core of IPC hardware system is the CPU. In addition, it also includes digital I/O interface, double frequency three-phase voltage transient surface to sampling interface, double frequency three-phase voltage steady-state surface to sampling interface, double frequency three-phase current steady-state surface to sampling interface, double frequency three-phase current transient surface to sampling interface, double frequency electrical frequency signal input interface, networking interface, display interface, printer interface and keyboard input Interface and power supply. Each part is an independent function module, and the data input and output modules are connected to each other via PCI bus. Double frequency voltage and current transient signal are processed and isolated through the transmitter or transformer in the measurement and control box, and then by the acquisition card enter into the computer signal from the acquisition card into the processor must be digital, so the acquisition card have AD acquisition channel, for transient data analysis needs, data acquisition rate and accuracy must meet the requirements, so the acquisition card surface to sampling rate and the number of bits and Cache size must have a certain request. Double frequency voltage and current steady-state signal through serial port of the various types of instruments on the panel enter into the computer. Double frequency electrical frequency signal is got by shaping the dual frequency voltage signal into TTL level square wave signal then enter into the computer, computer measured the frequency of it. Digital I/O is the digital input and output interfaces, mainly for the control of the load cabinet, including increased load, reduce load and unload control, power factor adjustment control, and load balancing control etc. The networking interface is used for computer network communication. Human-computer interaction can be achieved through LCD display of various data and curves, report print output, keyboard input and so on.

\section{System software design}

\section{Software requirements analysis}

Power vehicle double frequency unit electrical performance tester can complete the measurement and performance analysis of the generator's various electrical parameters mainly. Including the measurement and display of power frequency/intermediate frequency steady-state voltage, current, frequency, power, power factor, difference between the two phases; Waveforms, such as harmonic content, crest factor; steady-state voltage characteristics, such as steady-state voltage deviation, voltage imbalance, voltage deviation; transient voltage regulation and adjustment time; load control and regulation. Taking into account the generalization and expansion of the automatic test system, the system also has parameter input, automatic measurement, measurement results, storage, query and print function.

\section{Data flow diagram}

According to the software requirements analysis and the overall design idea, the data flow chart shown in Figure 2 is got.

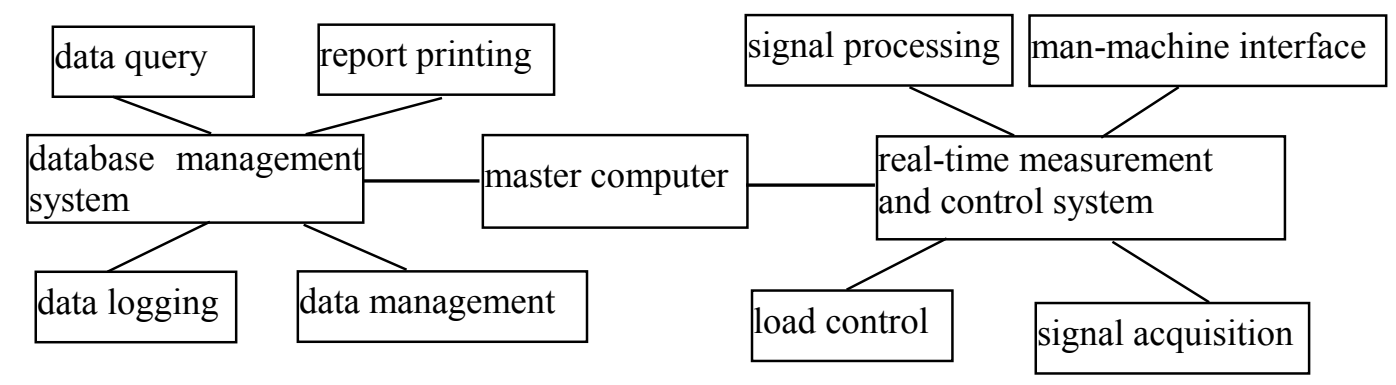

Fig.2 The data flow diagram 
Having the master computer as the core, all compose the real-time measurement and control system and database management system. Real-time measurement and control system include man-machine interface, load control, signal acquisition, signal processing, which constitute a virtual instrument test system. The database system can perform test data management, logging, query and report printing. Software platform and software structure

The system is based on windows XP operating system and LabView7.1 software development environment. The software adopts the virtual instrument technology, the steady state parameter digital table display and the transient parameter and the waveform oscilloscope display. The software system mainly includes generator test, load control, PC and secondary instrument communication, man-machine interface software, analog acquisition software, calculation and analysis software, report generation software, database management software and other parts. From the functional aspects the system can be divided into:

Real-time measurement and control unit for human-computer dialogue, output signal control and various types of signal acquisition and analysis processing.

Database unit for recording, querying, managing and printing of test result data.

\section{Conclusion}

The double frequency unit electrical performance tester of certain power vehicle is designed for power frequency and intermediate frequency generator test requirements specifically designed to solve the problem that domestic similar products can only carry out parameter detection of power frequency unit or intermediate frequency unit separately, also is a high-precision, high-speed generator electrical performance test and waveform analysis intelligent detection equipment. The tester has been used for certain surface to air missile weapons system power vehicle overhaul, every indicators are in line with GJB1488-92 and 2815-97 requirements, can be extended to units and related research institutions that carry out production and overhaul of the double frequency units, has a broad application prospects and development potential. The tester's human-computer interaction interface is friendly and beautiful, has high degree of automation, can greatly improve the test efficiency with high test accuracy and high accuracy.

\section{References}

1. Leszek S.Czarnecki. Power related phenomena in three-phase unbalance system[J]. IEEE Tranaction on Power Delivery, Vol.11 No.3, 1995:1168-1176

2. P Moore, D Carranza, A John. Model system tests on a new numeric Method of power system frequency measurement[J]. IEEE Transactions on Power Delivery, 1996,11(4):696-701

3. Sheng Kuang, Lai-Xuzhao. Condition monitoring and fault diagnosis of turbine generator unit[J], Microcomputer information, 2008 4-1:205-207

4. Gao-Xingsheng. Electrical performance comprehensive tester for an intelligent generator set[D].North China Electric Power University. 2001

5. GJB 1488-92. General test method of military internal combustion engine[S]

6. GJB 2815-97. General specification of military internal combustion engine station[S] 